\title{
Inter domain interactions influence the substrate affinity and hydrolysis product specificity of xylanase from Streptomyces chartreusis L1105
}

Ke Xiong ${ }^{1,2^{*}}$ D , Zi xiang Yan ${ }^{1,3}$, Jia yun Liu ${ }^{1,2}$, Peng gang Pei ${ }^{2,3}$, Lei Deng ${ }^{2,4}$, Le Gao ${ }^{1,2}$ and Bao guo Sun ${ }^{1,3}$

\begin{abstract}
Purpose: This study investigated the influence of inter-domain interactions on the substrate affinity and hydrolysis product specificity of xylanase.

Methods: Genes encoding a GH10 endo-xylanase from Streptomyces chartreusis L1105 xynA and its truncated derivative were cloned and expressed in Escherichia coli. The catalytic activities of the enzyme (xynA) and the derivative xynADCBM, lacking the carbohydrate binding module (CBM), were assessed to evaluate the role of CBM in xynA.

Results: Recombinant xynA ( $44 \mathrm{kDa}$ ) was found to be optimally active on beechwood xylan at $65^{\circ} \mathrm{C}$ with pH 7.7, while xynADCBM ( $34 \mathrm{kDa}$ ) exhibited optimal activity at $65^{\circ} \mathrm{C}$ with pH 7.2. Additionally, xynA and xynADCBM were found to be highly thermostable at $40-60{ }^{\circ} \mathrm{C}$, each retaining $80 \%$ of their original activity after $30 \mathrm{~min}$. The xynADCBM without the CBM domain was highly efficient at hydrolyzing xylan to produce xylobiose (over 67\%), which may be because the CBM domain facilitates substrate binding with xylanase. Meanwhile, the xylan hydrolysis efficiency of xynADCBM was higher than that of xynA.

Conclusion: These findings showed that the CBM domain with non-catalytic activity has no significant effect on the characteristics of the enzyme at optimum $\mathrm{pH}$ and $\mathrm{pH}$ tolerance. It has also been suggested that the derivative xynADCBM without CBM components can promote hydrolysis of xylan to yield xylooligosaccharides, which has great potential economic benefits.
\end{abstract}

Keywords: Streptomyces chartreusis L1105, Carbohydrate binding module (CBM), Substrate binding, Hydrolysis products

\section{Introduction}

Xylan is the main carbohydrate in hemicellulose, which constitutes $30-35 \%$ of the biomass of lignocellulose (Sousa et al. 2016). As a hydrolytic substrate, xylan is essential in the subsequent conversion steps that yield other value-added products from hemicellulosic materials

\footnotetext{
* Correspondence: xiongke@btbu.edu.cn

'Beijing Innovation Centre of Food Nutrition and Human, Beijing Technology \& Business University (BTBU), No. 33 Fucheng Road, Haidian, Beijing 100048, China

${ }^{2}$ Beijing Laboratory for Food Quality and Safety, Beijing Technology \& Business University (BTBU), No. 33 Fucheng Road, Haidian, Beijing 100048,

China

Full list of author information is available at the end of the article
}

(Petzold-Welcke et al. 2014). Furthermore, these steps require a series of hydrolytic enzymes to complete saccharification. Xylanase plays an important role in xylan hydrolysis by catalyzing the hydrolysis of 1,4-D xylosidic linkages in xylan to yield short xylooligosaccharides (XOS), which have great potential economic benefits.

Xylooligosaccharides are oligomers containing 2-7 xylose molecules linked by $\beta$ (1-4) glycosidic bonds (Bian et al. 2013), which are obtained by the degradation of xylans via chemical, physical, and enzymatic degradation process. Xylooligosaccharides have a variety of biological activities, such as promoting the growth of beneficial intestinal bacteria (Samanta et al. 2015), accelerating the metabolism of

(c) The Author(s). 2020 Open Access This article is licensed under a Creative Commons Attribution 4.0 International License, which permits use, sharing, adaptation, distribution and reproduction in any medium or format, as long as you give appropriate credit to the original author(s) and the source, provide a link to the Creative Commons licence, and indicate if changes were made. The images or other third party material in this article are included in the article's Creative Commons licence, unless indicated otherwise in a credit line to the material. If material is not included in the article's Creative Commons licence and your intended use is not permitted by statutory regulation or exceeds the permitted use, you will need to obtain permission directly from the copyright holder. To view a copy of this licence, visit http://creativecommons.org/licenses/by/4.0/ 
fat, improving the absorption of calcium, preventing dental caries, and acting as antioxidants (Ramkrishna et al. 2015). The enzymatic hydrolysis of pretreated hemicelluloses biomass is an ideal alternative for XOS production comparable to physical and chemical methods. When XOS, such as xylobiose and xylotriose, were produced in response to hydrolyzation by xylanase, they generally comprised less than $30 \%$ of the hydrolysate. Furthermore, the hydrolysate contained large amounts of xylose and arabinose, which are not biologically active. Accordingly, more complex processes are required to improve the purity $(60-70 \%)$ of functional hydrolysates; however, such processes are expensive. Therefore, the enzymatic hydrolysis of hemicellulose and its sources should be optimized to enable efficient XOS production (Otieno and Ahring 2012). Because of the high demand for xylanases, those from the glycoside hydrolase (GH) family, especially the GH10 and GH11 xylanases of microorganisms, have been investigated in detail.

The GH10 (MW > $30 \mathrm{kDa}$ with low pI values) and GH11 (MW < $30 \mathrm{kDa}$ and high pI values) families have been classified based on their amino acid sequence similarities and hydrophobic cluster analysis (Xiao et al. 2014). The two families of xylanases also differ in the patterns of cleavage of various heteroxylans. For example, GH10 xylanase is thought to be a useful candidate for the digestion of native branched xylan and for producing lower molecular weight xylooligosaccharides. GH11 xylanase has relatively high specificity hydrolysis for xylan, and the main product of xylanase hydrolysis is xylose. In addition to a catalytic domain in GH11, some GH10 xylanases also have other various non-catalytic domains, such as the carbohydrate binding module (CBM) (Falck et al. 2013; Sermsathanaswadi et al. 2017), which currently has an unknown function. This domain can promote the affinity of enzymes toward their substrates. In addition, it may promote synergies with a multi-enzyme system to degrade the substrate (Shin et al. 2002; Kumar and Satyanarayana 2014).

In a previous study, we isolated the cellulase-free xylanase-producing bacterium Streptomyces chartreusis L1105 (Zhu et al. 2012). Despite the apparent utility of xylanase from strain L1105 as an XOS-reducing biocatalyst, its properties have not been fully investigated. Therefore, in this study, we characterized the xylanase gene of strain L1105 (GH10) and examined the effect of inter-domain interactions (catalytic domain and other various supplementary domains) on the catalytic activity of xylanase from strain L1105 and the production of XOS.

\section{Material and methods}

Bacterial strains, vectors, and culture conditions

Streptomyces chartreusis L1105 was kept in the lab after isolation from a soil sample under a decaying tree fiber layer in the Anhui Province in China and identification using the 16S rRNA method (Zhu et al. 2012). Competent Escherichia coli DH5 $\alpha$ (Takara Bio Inc., Shiga, Japan) and competent E. coli BL21 (DE3) (TransGen Biotech Company, Beijing, China) were used as recipient bacteria for transformation and expression, respectively. Plasmids pMD18-T (Takara Bio Inc., Shiga, Japan) and pET-28a (+) (EMD Biosciences, San Diego, CA, USA) were used as the vectors for gene cloning, sequencing, and expression. Luria Broth (LB) liquid medium was used to culture the strain L1105 (pH 7.0).

E. coli $\mathrm{DH} 5 \alpha$ (contained with pMD18) recombinant plasmid was cultivated in an LB culture medium at $37{ }^{\circ} \mathrm{C}$ while being shaken at $200 \mathrm{rpm}$. E. coli BL21 (DE3) pET-28a recombinant plasmid was cultivated in LB culture medium at $37{ }^{\circ} \mathrm{C}$ while being shaken at $200 \mathrm{rpm}$. Xylose (X1), xylobiose (X2), xylotriose (X3), and xylotetraose (X4) were provided by Megazyme (Bray, Ireland). All other substrates, including beechwood xylan and oat spelt xylan, were obtained from Sigma-Aldrich (St. Louis, Mo, USA). All other chemicals used were chromatographic grade.

\section{Construction of genomic DNA library and polymerase chain reaction}

Strain L1105 was cultivated in LB liquid culture medium for $72 \mathrm{~h}$ at $30{ }^{\circ} \mathrm{C}$ with $\mathrm{pH} 7.0$ while being shaken at 150 rpm. Genomic DNA extraction of $x y n A$ was accomplished using a TianGen kit (TianGen Biotech Company, Beijing, China) according to the manufacturer's instructions. Genomic DNA was amplified by degenerate primers (Table S1), which were designed based on the $\mathrm{N}$-terminal amino acid sequence of the native xylanase from strain L1105 compared with other xylanases from Streptomyces reported in GenBank (Gibbs et al. 2001; Bergquist et al. 2005; Padilla-Hurtado et al. 2012). Phylogenetic trees were then constructed for homology analysis. Degenerate primers were designed through the conserved sequences of these genes. The primers were then used to amplify the core sequence of xynA (xynACore) using the bacterial genome of strain L1105 as a template (Figure S2, Tables S2 and S3). The polymerase chain reaction (PCR) program was 30 cycles of denaturation $\left(30 \mathrm{~s}\right.$ at $\left.94{ }^{\circ} \mathrm{C}\right)$, annealing $30 \mathrm{~s}$ at $62{ }^{\circ} \mathrm{C}$, and extension $60 \mathrm{~s}$ at $72{ }^{\circ} \mathrm{C}$. The PCR products were then cloned into the pMD18-T vector for sequencing analysis.

\section{Nucleotide sequence analysis}

The nucleotide sequence of the insert was analyzed by primer walking, and the open reading frames (ORFs) were analyzed by NCBI sequence analysis (http://www.ncbi. nlm.nih.gov/gorf/gorf.html). A homology search was conducted using the GenBank BLAST program (http://blast. ncbi.nlm.nih.gov/Blast.cgi). Multiple alignments were then 
conducted using the signal peptide prediction program (http://www.cbs.dtu.dk/services/SignalP), the conserved domain database (http://www.ncbi.nlm.nih.Gov/structure/ cdd/cdd.shtml), and the catalytic sites prediction database (http://prosite.expasy.org/). The 3D structure model has been established based on the structure, and the sequence was highly conserved in the catalytic domain. The 3D structure of xylanase from strain L1105 was constructed using the SWISS-MODEL and analyzed by AutoDockTools-1.5.6 (Ravi et al. 2015).

\section{Construction of derivatives of $x y n A$}

The E. coli strain DH5 $\alpha$ was used in conjunction with the pET28a vector to construct plasmids (Zhang et al. 2002). For the construction of plasmids that encode full-length $x y n A$, the CBM of $x y n A(C B M)$, and a derivative of $x y n A$ that contains no sequences of CBM ( $x y n A D C B M)$ as well as nucleotides for amino acids $1-460$, which encode the full length of the $x y n A$ gene, were amplified using the primers 5'-CCGAATTCATGGCGACCCGCACATCC AT-3' (XynF) and 5'-CCCTCGAGTCAGGACGCC GTGCAGGAAC-3' (XynR). The primers were designed to obtain the $x y n A D C B M$ ORF without CBM structure and a CBM ORF that only encoded CBM. The region of the $x y n A$ gene between nucleotides for amino acids $1-345$, which encodes the $x y n A D C B M$ gene without the linker sequence, and $C B M$ was amplified using the primers $\mathrm{XynF}$ and 5'-CCCTC GAGCAGCGTCGCTGTGTA-3' (Xyn$\mathrm{ReC}$ ), while the region of $x y n A$ gene encoding only the CBM was amplified by PCR using 5'-CCGAATTCTG CACGGCCACCTACAGC-3' (XynFeC) and XynR. All PCR products were amplified under the following conditions: denaturation at $94{ }^{\circ} \mathrm{C}$ for $4 \mathrm{~min}$ followed by $30 \mathrm{cy}-$ cles of denaturation at $94{ }^{\circ} \mathrm{C}$ for $30 \mathrm{~s}$, annealing at $68{ }^{\circ} \mathrm{C}$ for the $30 \mathrm{~s}$ and polymerization at $68{ }^{\circ} \mathrm{C}$ for $30 \mathrm{~s}$, and a final extension at $72{ }^{\circ} \mathrm{C}$ for $60 \mathrm{~s}$. These amplified DNA sequences were purified and ligated into a pMD18-T vector. All amplified DNA sequences were resequenced using a PRISMTM ready reaction dye deoxy terminator cycle sequencing kit and an Applied Biosystems ABI 373A sequencer (Thermo Fischer Scientific, Waltham, MA, USA) to verify that no mutations were generated during PCR (Black et al. 1996).

\section{Purification of xynA and truncated derivatives}

To construct a recombinant plasmid, the gene fragment of xylanase from pMD18-T encoding the extracellular region was ligated in frame with cleavage sites EcoRI and XhoI of the pET28a vector to generate pET28axynA, pET28a-xynADCBM, and pET28a-CBM. These expression vectors were transformed into $E$. coli Rosettagami B (DE3) (Novagen, Darmstadt, German) by the heat shock method (Michael and Joseph 2012), then selected on LB agar supplemented with kanamycin $(40 \mu \mathrm{g} /$
$\mathrm{mL}$ ) at $37{ }^{\circ} \mathrm{C}$ for $24 \mathrm{~h}$. The positive clones successfully transformed on the medium containing kanamycin were selected for isopropyl- $\beta$-D-thiogalactoside (IPTG) induction expression. Then, the positive clones were transferred into LB medium and cultured at $37{ }^{\circ} \mathrm{C}$ with 200 $\mathrm{rpm}$. When the optical density (OD) of culture medium was 0.6 , added with IPTG whose final concentration was $1 \mathrm{mM}$, the xylanase expression was induced by IPTG at $16{ }^{\circ} \mathrm{C}$ overnight. The cells were then collected by centrifugation at $2290 \times g$ for $5 \mathrm{~min}$ then were washed twice with an acetic acid buffer solution (0.02 M, pH 5.5), after which they were subjected to the ultrasonic breaking of the cell walls using an ultrasonic cell crusher XO-650 (Nanjing SiNo Technology, Nanjing, China). Disrupted cells were then centrifuged at $13,200 \times g$ for $30 \mathrm{~min}$ to remove cell debris and unbroken cells. Ten microliter of supernatant was spot on the plate (Agar $1.5 \%(\mathrm{w} / \mathrm{v})$, Beechwood xylan $0.5 \%, 0.1 \mathrm{~mol} / \mathrm{L}$ imidazole at $121{ }^{\circ} \mathrm{C}$ sterilizing for $20 \mathrm{~min}$ ) and placed in incubator at $50{ }^{\circ} \mathrm{C}$ for $60 \mathrm{~min}$. Dye with $1 \%$ Congo red for $20 \mathrm{~min}$ and decolorize with $1 \% \mathrm{NaCl}$. If there is any transparent band around the spot of supernatant, it means that xylanase is contained in supernatant. Next, selected $E$. coli transformants were grown in LB until the optical density at $600 \mathrm{~nm}$ reached $0.6-0.8$, at which time IPTG was added to a final concentration of $0.1 \mathrm{mM}$, and the culture was cultivated at $16{ }^{\circ} \mathrm{C}$ for $16 \mathrm{~h}$. The cells were then collected by centrifugation at $2290 \times g$ for $5 \mathrm{~min}$ then washed twice with an acetic acid buffer solution $(0.02 \mathrm{M}$, $\mathrm{pH}$ 5.5), after which they were subjected to the ultrasonic breaking of the cell walls using an ultrasonic cell crusher XO-650 (Nanjing SiNo Technology, Nanjing, China). Disrupted cells were then centrifuged at 13, $200 \times \mathrm{g}$ for $30 \mathrm{~min}$ to remove cell debris and unbroken cells.

The resultant supernatant was heated at $65{ }^{\circ} \mathrm{C}$ for 10 min then centrifuged to remove precipitates. The supernatant obtained was purified by $\mathrm{Ni}^{2+}$ immobilized metal ion affinity chromatography on a Sepharose 6 fast flow column (GE Healthcare, Pittsburgh, USA) according to the manufacturer's instructions. The active fraction was applied to a CM-Sepharose FF column (GE Healthcare, Pittsburgh, USA) equilibrated with $50 \mathrm{mM}$ phosphate buffer ( $\mathrm{pH} 8.0$ ) plus $0.5 \mathrm{M} \mathrm{NaCl}$, then eluted with the same buffer. The column was equilibrated before protein binding with $50 \mathrm{mM} \mathrm{NaH} \mathrm{PO}_{4} \quad(0.5 \mathrm{M} \mathrm{NaCl}, 0 \mathrm{mM}$ Imidazole, $\mathrm{pH}$ 8.0), after which the supernatant containing protein was bound to the column for $30 \mathrm{~min}$. Next, nonspecific bound proteins were removed by washing the column with $50 \mathrm{mM} \mathrm{NaH}_{2} \mathrm{PO}_{4}(0.5 \mathrm{M} \mathrm{NaCl}, 5 \mathrm{mM}$ Imidazole, $\mathrm{pH}$ 8.0). Specifically, the bound proteins were then eluted with different concentrations of a $\mathrm{NaH}_{2} \mathrm{PO}_{4}$ imidazole buffer solution, after which the recombinant protein was measured based on the ultraviolet signal at 
$280 \mathrm{~nm}$. The purity of fractions was confirmed by SDSPAGE.

\section{Characterization of recombinant xynA and its truncated derivatives}

To determine the xylanase activity, a suitably diluted xylanase was added to $10 \mathrm{~g} / \mathrm{L}$ birchwood xylan substrate. The reaction was conducted at $\mathrm{pH} 5.4$ and $55{ }^{\circ} \mathrm{C}$ for 5 min along with heat-inactivated xylanase as a control, after which it was stopped by adding $1 \mathrm{~mL}$ of 3,5-dinitrosalicylic acid (DNS) solution. The released reducing sugars were measured by the DNS method using X1 as a standard. The active unit of xylanase was defined as the quantity required to produce $1 \mu \mathrm{mol}$ xylose every minute (U) (Miller 1959).

The $\mathrm{pH}$ profile of purified recombinant xynA and xynADCBM was determined by measuring the enzyme activity at $50{ }^{\circ} \mathrm{C}$ in buffers of varying $\mathrm{pH}$ from 2.2 to 11.3 (citric acid buffer, pH 2.2-4.2; acetic acid buffer, pH 3.8-5.8; MES buffer, pH 5.2-7.2; MOPS buffer, 6.28.2; Tris- $\mathrm{HCl}$ buffer, 7.0-9.0; CHES buffer, $\mathrm{pH}$ 8.2-10.2; CAPS buffer, $\mathrm{pH}$ 9.3-11.3). To determine the $\mathrm{pH}$ stability, the enzyme was pre-incubated in different $\mathrm{pH}$ buffers for $30 \mathrm{~min}$ at $50{ }^{\circ} \mathrm{C}$, after which the substrate was added to determine the residual enzyme activity. The initial activity at optimum $\mathrm{pH}$ has been defined to $100 \%$ before incubation. Assays at different temperature values $\left(40-90{ }^{\circ} \mathrm{C}\right)$ were performed, and the enzyme was preincubated for $10 \mathrm{~min}$ at different temperatures to determine the optimal temperature. To determine the thermal stability, the enzyme was pre-incubated at different temperatures for $30 \mathrm{~min}$ in an optimum $\mathrm{pH}$ buffer system. The reaction was subsequently terminated by incubation in ice water, after which the relative enzyme activity was calculated and compared with that of the untreated enzyme.

\section{Effects of metal ions on recombinant xynA and its truncated derivatives}

The effects of metal ions on the enzyme activities were determined by incubating the enzymes in the presence of $1 \mathrm{mM}$ of $\mathrm{CaCl}_{2}, \mathrm{CoCl}_{2}, \mathrm{NaCl}, \mathrm{CuCl}_{2}, \mathrm{MgCl}_{2}, \mathrm{MnCl}_{2}$, $\mathrm{ZnCl}_{2}, \mathrm{FeCl}_{2}, \mathrm{FeCl}_{3}$, and $\mathrm{AgCl}$. The residual activity was measured and compared with that of control without additive.

\section{The specificity of recombinant xynA and its truncated derivatives}

To determine the substrate specificity of the enzyme, the recombinant xynA and its truncated derivatives were incubated with $1 \%(\mathrm{w} / \mathrm{v})$ of each substrate (birchwood, beechwood, oat-spelt, wheat bran, corncob, and beanstalk xylan) in $50 \mathrm{mM}$ MOPS buffer ( $\mathrm{pH} \mathrm{8.2)}$ at $50{ }^{\circ} \mathrm{C}$ for $10 \mathrm{~min}$. The released reducing sugars were estimated using the DNS method as described previously. The ratio of xylanase activity for other substrates and the activity for birchwood xylan was defined as relative enzyme activity.

\section{Binding of the CBM domain with the substrate}

Insoluble xylan and microcrystalline cellulose were selected as experimental objects to study the binding of xynA, xynADCBM, or CBM recombination protein to these insoluble polysaccharides. xynA, xynADCBM, and CBM fragments were mixed with the xylan and microcrystalline cellulose substrate then washed with washing buffer to remove nonspecific binding proteins from the substrate. If the binding of proteins and substrate were nonspecific, the nonspecific binding proteins in washing buffer would be detected by SDS-PAGE. The specifically bound protein-substrate complex is then denatured to discharge the specifically bound protein. If proteins and substrate are specifically bound, the specific binding proteins would be detected by SDS-PAGE after denaturation. This method was used to distinguish specific and nonspecific binding between the enzyme and substrate (Figure S3). Briefly, $80 \mu \mathrm{L}$ of xynA, xynADCBM, or CBM recombination protein was added to $150 \mu \mathrm{L}$ of acetate buffer solution $(20 \mathrm{mM}, \mathrm{pH} 5.3)$. After mixing, about $30 \mu \mathrm{L}$ of the sample was taken from each experimental group as a control. Then, the remaining $200 \mu \mathrm{L}$ reaction solution (acetic acid buffer, pH 5.3) was mixed with 20 $\mathrm{mg}$ xylan and $20 \mathrm{mg}$ microcrystalline cellulose substrate respectively. The reaction was conducted in an ice bath for more than $1 \mathrm{~h}$ while inverting and rotating the tubes to ensure binding equilibrium. Samples were then centrifuged at $15,490 \times g$ for $10 \mathrm{~min}$, after which the supernatant and precipitate were collected. The precipitate was washed with reaction buffer and resuspended with $10 \%$ SDS buffer. The binding protein in the precipitate was inactivated by incubation in a boiling water bath for $10 \mathrm{~min}$. Next, the protein in the re-supernatant solution was analyzed by SDS-PAGE to ensure the binding status of protein with the substrate.

\section{Analysis of the products of xylan substrate hydrolyzed by the enzyme}

Each xynA or xynADCBM with $50.0 \mathrm{U}$ activity was then added to a $1 \%$ beechwood or oat spelt xylan substrate in $10 \mathrm{~mL}$ of phosphate buffer (pH 7.7 or 7.2) and then incubated at $50{ }^{\circ} \mathrm{C}$ for $12 \mathrm{~h}$ in a thermostatic bath shaking at $150 \mathrm{rpm}$ (DSHZ-300AH constant thermostatic bath shaker, Jintan Instrument Plant, Jiangsu, China). Next, $0.5 \mathrm{~mL}$ of the sample was recycled and filtered using a $0.2-\mu \mathrm{m}$ membrane filter. Xylose (X1), xylobiose (X2), xylotriose (X3), and xylotetraose (X4) were subsequently determined by high-performance liquid chromatography HPLC (1260 model, Agilent Technologies, Santa Clara, 
CA, USA) using a Shodex KS-802 analytical column (KS-802 Sugar analysis column, Showa Denko, Tokyo, Japan) equipped with a refractive index detector (Agilent Technologies, Santa Clara, CA, USA) (Sun et al. 2008).

The following formulas were used to determine the concentrations of xylose, xylobiose, and xylotriose:

$$
\begin{aligned}
& \mathrm{X} 1=(\mathrm{Y} 1-1180.9) / 102,165.2 \\
& \mathrm{X} 2=(\mathrm{Y} 2+2311.9) / 11,923.9 \\
& \mathrm{X} 3=(\mathrm{Y} 3-737.6) / 106,851.1 \\
& \mathrm{X} 4=(\mathrm{Y} 4+4057.9) / 171,785
\end{aligned}
$$

$\mathrm{X} 1, \mathrm{X} 2, \mathrm{X} 3$, and $\mathrm{X} 4$ are concentrations of xylose, xylobiose, xylotriose, and xylotetraose, respectively, and Y1, Y2, Y3, and Y4 are their respective peak areas. Experimental conditions are as follows: the mobile phase was acetonitrile/high pure water $(70 / 30, \mathrm{v} / \mathrm{v})$ at $0.6 \mathrm{~mL} / \mathrm{min}$, the column temperature was at $80{ }^{\circ} \mathrm{C}$, and the refractive detector temperature was at $45{ }^{\circ} \mathrm{C}$ with a $10 \mu \mathrm{L}$ sample injection. Each chromatographic analysis was performed three times to carry out parallel sample analysis.

\section{Results}

\section{HiTAIL-PCR obtained the full-length gene of xylan}

BLAST analysis of the $15 \mathrm{~N}$-terminal amino acids sequences of xylanase from strain L1105 in the NCBI database revealed 80 xylanase encoded gene sequences of Streptomyces sp. Phylogenetic trees revealed a close homology of 10 xylanase encoded gene sequences from Streptomyces sp. (Figure S1). The 874 bp core sequence of $x y n A$ ( $x y n A$-Core) was used to amplify by the primers (Table S1) using the bacterial genome of strain L1105 as a template (Figure S2, Tables S2 and S3). The core sequence of the xylanase gene was analyzed using NCBI BLAST, and the results showed that the gene sequence was highly homologous with these gene sequences in GenBank (Accession numbers HE971709.1, AF194024, and AB110643.1). Taken together, these findings indicate that the core sequence obtained can encode a xylanase.

Following the HiTAIL-PCR process, the C-terminal flanking sequence of $x y n A-3$, which had sizes of $1000 \mathrm{bp}$ and $2000 \mathrm{bp}$, was obtained in two rounds of PCR processing (Liu and Chen 2007). Moreover, the N-terminal flanking sequence $x y n A-5$ with $1200 \mathrm{bp}$ was also obtained. The core sequence was eventually produced due to the overlapped parts of the $\mathrm{C}$ - and $\mathrm{N}$-terminal flanking amplicons. The DNAMAN software was used to analyze the sequence of $x y n A-3$ combined with $x y n A-5$. A full-length gene $x y n A$ (1381 bp) was found with an initiation codon ATG and termination codon TGA.

\section{Analysis of the $x y n A$ gene and domain}

BLAST searches revealed that 51 sequences were more than $70 \%$ homologous with the sequence of $x y n A$ from strain L1105 in the NCBI database. The gene is highly homologous with the xylanase encoding genes from Streptomyces megasporus (HM003041.1, 81\%) (Chitte and Dey 2001), Streptomyces halstedii (U41627.1, 81\%) (Ruizarribas et al. 1995), and Streptomyces chattanoogensis (AF121864.2, $74 \%)$. These findings illustrate that the gene is novel and worthy of further study. The xynA gene from strain L1105 was cloned by PCR and HiTAIL-PCR. Bioinformatics analysis revealed that the full-length gene of $x y n A$ is $1383 \mathrm{bp}$, and the G-C content is $68.5 \%$ (Fig. 1a). The sequence of xynA encodes 460 amino acids, and this protein has a molecular weight of about $48.2 \mathrm{kDa}$. The isoelectric point of the protein is 9.04. The signal peptide of xylanase was predicted to be MATRTSIDPPPE RRPRRSRVRTALALGLA GLLGATGVGALTGTAQA. Taken together, these findings indicate that the protein encoded by this gene sequence can secrete extracellular substances (Fig. 1b). Additionally, there was a significantly conserved area belonging to the group 10 family of glycoside hydrolase and a sequence encoding non-catalytic areas, known as the carbohydrate binding module (CBM), which excludes the catalytic domain (Fig. 1c). The predicted protein domain showed that the amino acids from 57 to 345 form a Glyco hydro10 domain (catalytic domain) with an $e$ value of $1.31 \mathrm{e}^{-173}$, which is lower than $10 \mathrm{e}^{-6}$, indicating that the structure prediction was reliable (Liu 2005). The amino acids from 362 to 460 form a carbohydrate binding module that belongs to the CBM_2 superfamily. Two tryptophan residues are involved in cellulose binding. The twinarginine translocation signal profile located in the function region is part of the signal peptide, which is encoded by amino acids 1 to 46 . Functional region analysis predicted a catalytic site at the 173rd glutamate for the proton donor and the 281st glutamate for the nucleophile (Fig. 1c). The molecular weights of the family 10 xylanases were mostly larger than $30 \mathrm{kDa}$ with a composite structure domain.

\section{Purification of xynA and truncated derivatives and their characterization}

Full-length and two truncated derivatives of the $x y n A$ gene were expressed in a segmentation way. The $x y n A D C B M$ does not contain linker sequences or $C B M$, while $C B M$ was joined by a small linker sequence region (Fig. 2a).

The xynA (1383 bp) and two truncated (xynADCBM, $1023 \mathrm{bp} ; C B M, 360 \mathrm{bp}$ ) derivatives of the $x y n A$ encoding gene were cloned and successfully expressed in $E$. coli. (Fig. 2b). A 2.17-fold xynA purification was achieved with a $27.23 \%$ recovery of xylanase activity, while a 2.64 fold xynADCBM purification was achieved with a $21.49 \%$ recovery of xylanase activity. The specific activity 

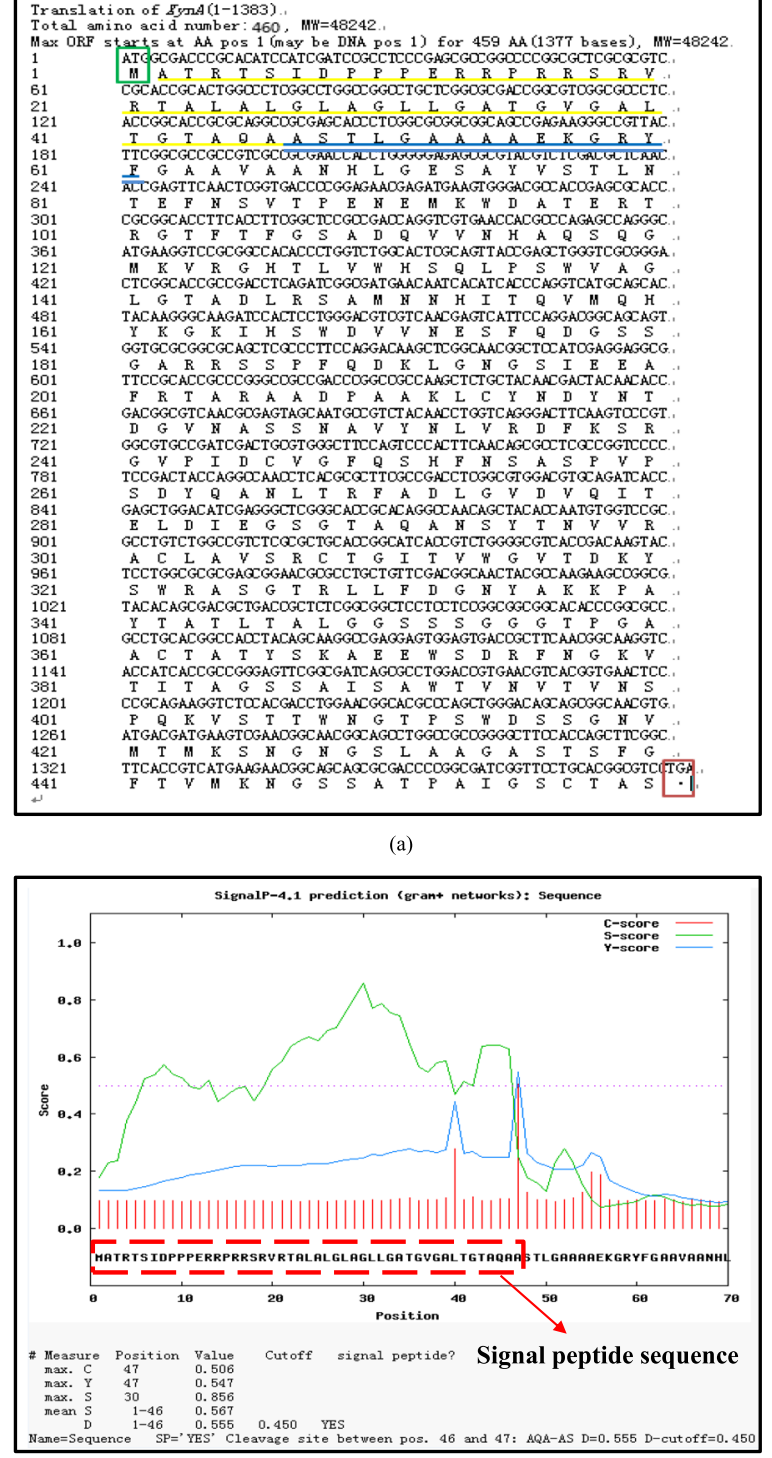

(b)

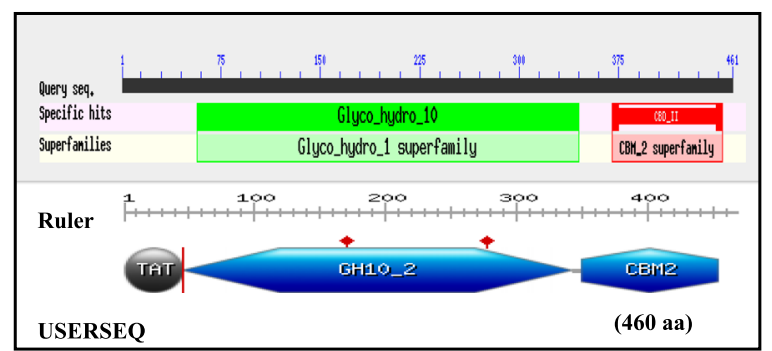

(c)

Fig. 1 The bioinformatics analysis of Xylanase from Streptomyces chartreusis L1105. a Gene and amino acid sequence. The underlined is signal peptide, double underlined is 15 amino acid sequence of N-terminal. b Prediction of signal peptide. c Prediction of conserve domain and the catalytic site (red dot marked in the figure) of xylanase of purified xynA and xynADCBM increased from 105.06 to $228.12 \mathrm{U} / \mathrm{mg}$ and 125.11 to $330.43 \mathrm{U} / \mathrm{mg}$, respectively. A summary of the purification of xynA and xynADCBM is presented in Table S4.

As shown in Fig. 2c, SDS-PAGE visualized using Coomassie blue revealed that the purified enzymes contained a single band with relative molecular mass $(\mathrm{Mr})$ values of $44 \mathrm{kDa}$ (xynA), $34 \mathrm{kDa}$ (xynADCBM), and $10 \mathrm{kDa}$ (CBM). The sizes of the three forms of xynA were similar to their predicted molecular mass values according to their deduced primary sequence data (Fig. 1a).

xynA has an optimum of $\mathrm{pH} 7.7$ with a range of 2.211.3, while xynADCBM has an optimum $\mathrm{pH}$ value of 7.2 (Fig. 3a, b). Similar to some recombinant endo-xylanases from other Streptomyces sp., these enzymes showed activity at broad $\mathrm{pH}$ ranges of 7-8, while they were less active under acidic conditions ( $\mathrm{Fu}$ 2010; Deesukon et al. 2011). However, xynA and xynADCBM both retained $80 \%$ activity at $\mathrm{pH} 6.2-10.3$ at $50{ }^{\circ} \mathrm{C}$ for $30 \mathrm{~min}$. Taken together, these findings showed that the CBM domain with no catalytic activity had no significant effect on the characteristics of enzymes at the optimum $\mathrm{pH}$ or the range of tolerated $\mathrm{pH}$ values (Fig. 3c, d).

In addition to a partially alkaline $\mathrm{pH}$, thermostability is an ideal attribute for the industrial application of an enzyme. A longer active life of the enzyme during hydrolysis will lead to reduced enzyme dosage, thereby making the process cost-effective. It was reported that XSC738 endo-xylanase from thermo-acidophilic S. coelicolor Ac738 exhibited only $20 \%$ of the initial activity at $60{ }^{\circ} \mathrm{C}$ for $1 \mathrm{~h}$, while about $1 \%$ activity was detected for $5 \mathrm{~min}$ at $70{ }^{\circ} \mathrm{C}$ (Lisov et al. 2013), and SB-9a from Ziziphus mauritiana at $55{ }^{\circ} \mathrm{C}$ only maintained $50 \%$ of its activity for 10 min (Chivero et al. 2001). Temperature analyses of xylanase from S. chartreusis L1105 showed that the maximum activity of purified xynA occurred at $65{ }^{\circ} \mathrm{C}$. The activity of xynA increased linearly as the temperature increased to $65{ }^{\circ} \mathrm{C}$, after which it declined to $85 \%$ and $50 \%$ of the maximum at $70{ }^{\circ} \mathrm{C}$ and $80{ }^{\circ} \mathrm{C}$, respectively. Similar results were found for xynADCBM, which also showed a temperature optimum of $65{ }^{\circ} \mathrm{C}$ (Fig. 3e). The temperature stability of xynA and xynADCBM was determined at $40-80{ }^{\circ} \mathrm{C}$. The xynA and xynADCBM both retained $80 \%$ residual enzyme activity at $40-60{ }^{\circ} \mathrm{C}$ for $30 \mathrm{~min}$, indicating that the CBM domain with noncatalytic activity had no significant effect on the temperature tolerance of $x y n A$ and xynADCBM (Fig. 3f). A comparison of the properties of xynADCBM and xynA with different molecular weights revealed that most of the enzymatic properties of these two enzymes are similar. However, there are some significant differences between xynADCBM and xynA (Table 1), such as the effects of $\mathrm{Co}^{2+}$ ions on the enzyme activity. $\mathrm{Co}^{2+}$ has a significant effect on promoting the activity of 
xynA

$\square^{46} \quad{ }^{57} \quad 345 \quad 362 \quad 460$

xynADCBM

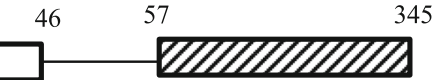

CBM

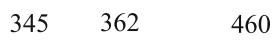

(a)
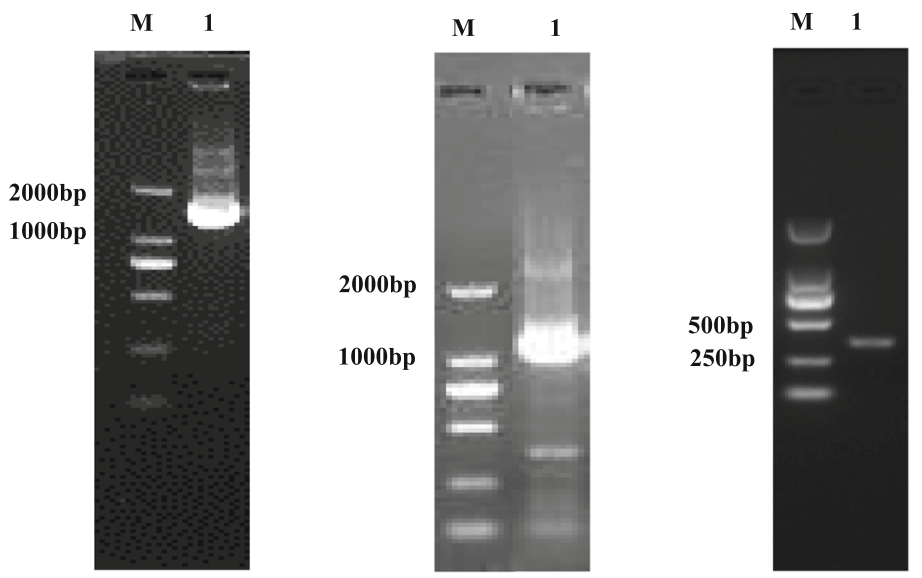

pET28a-xynA

pET28a-xynADCBM

pET28a-CBM

(b)

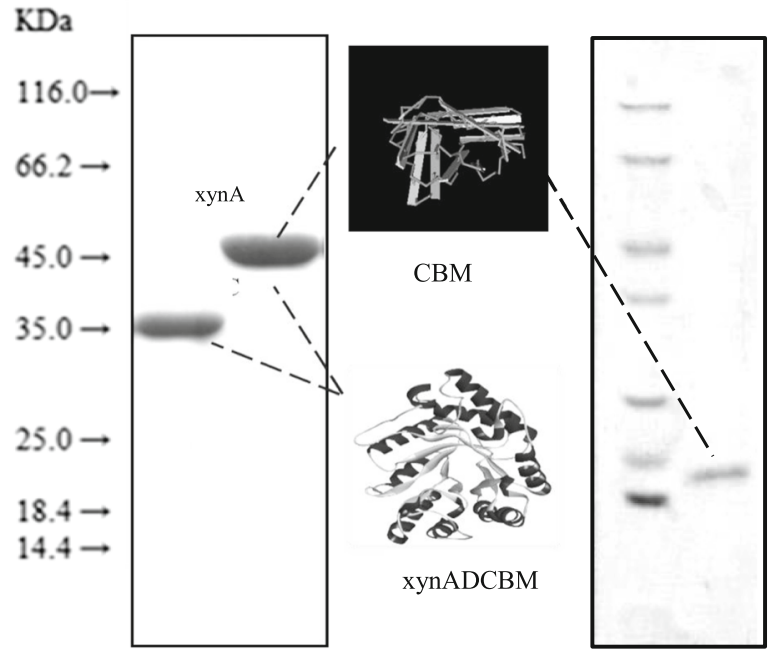

(c)

Fig. 2 Segmentation expression of $x y n A$ gene. a Structure of $x y n A$, xynADCBM, and CBM. The nucleotides for amino acids regions of $x y n A$ and

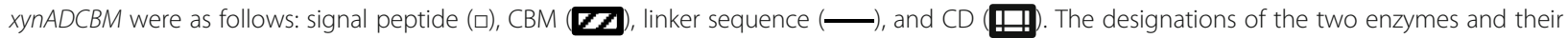
encoding plasmids are defined. $x y n A D C B M$ was derived by remove CBM domain from the xynA as described in the "Materials and methods" section. The position of the amino acids at the extremities of the CBMs and CDs, in the respective full-length native enzymes, is indicated. The size of the signal peptide in xynA and xynADCBM is 46 amino acids. The size of the CBM in xynA or xynADCBM is 98 amino acids and corresponds to residues 362 or 460 in the full-length sequence. b Recombinant plasmid of pET28a-xynA, pET28a-xynADCBM, and pET28a-CBM examined with nucleic acid electrophoresis. c Recombinant protein of pET28a-xynA, pET28a-xynADCBM, and pET28a-CBM examined with SDS-PAGE 

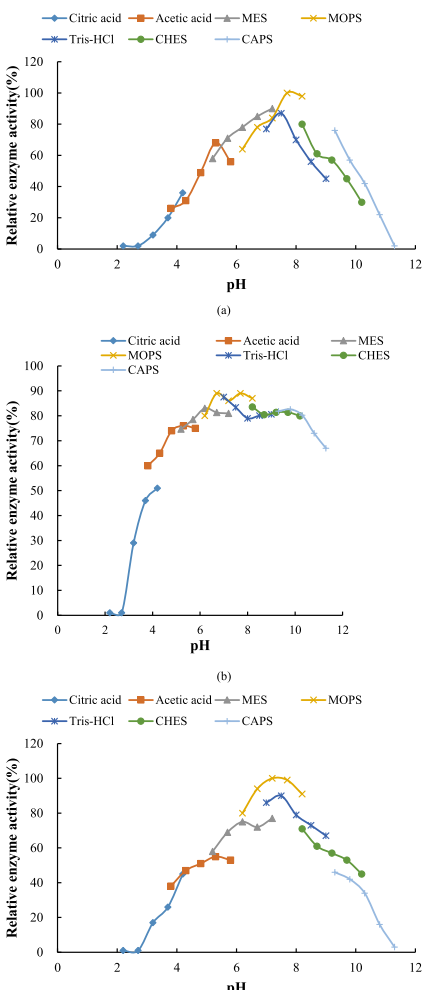

$\mathrm{pH}$
(c)

$\rightarrow$ - Citric acid $-\rightarrow$-Acetic acid $\rightarrow-$ MES $\quad *$ MOPS
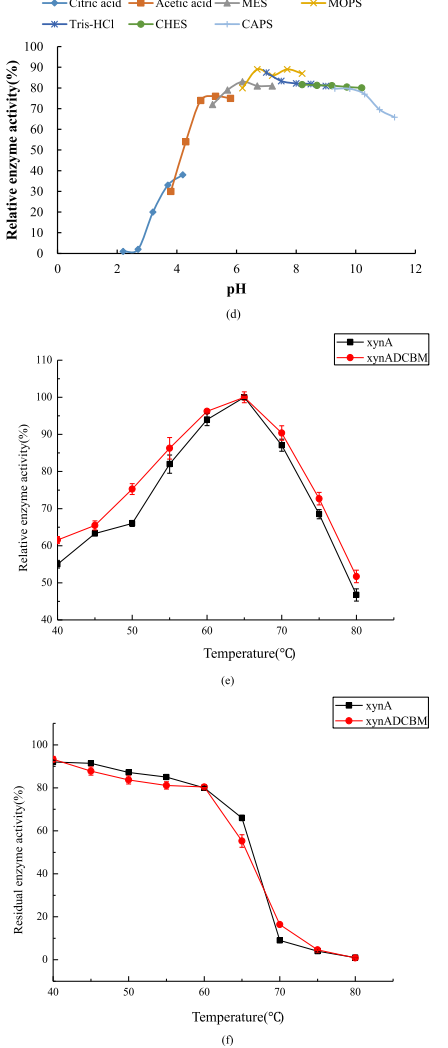

Fig. 3 The properties of $x y n A$ and truncated derivatives. a Optimal pH of xynA. $\mathbf{b}$ pH stability of xynA. $\mathbf{c}$ Optimal pH of xynADCBM. $\mathbf{d}$ $\mathrm{pH}$ stability of $x y n A D C B M$. e Optimum temperature of $x y n A D C B M$ and xynA. $\mathbf{f}$ Temperature stability of xynADCBM and xynA

xynADCBM $(34 \mathrm{kDa})$, but it also inhibits the activity of xynA $(44 \mathrm{kDa})$. Differences in the enzymatic properties between xynADCBM and xynA were also shown, indicating that the CBM structure could increase the efficiency of xylanase hydrolysis activity toward wheat bran and bean stalk xylan. The CBM structure can increase the affinity of xylanase binding to xylan substrate.

\section{Catalytic and cellulose-binding activity of xynA and its derivatives}

Experiments were conducted to explore the binding reaction of the three recombinant proteins, xynA, xynADCBM, and CBM, to substrate.

As shown in Fig. 4a, the binding of xynA and the xylan substrate produced no protein band in lane 2, indicating that the protein bound almost completely to the substrate. Moreover, no protein bands were present in lane 3 , indicating that all nonspecifically bound proteins had been removed by washing buffer. Lane 4 showed the removal of specific binding of the enzyme protein after SDS-boiling denaturation from the substrate, while xynADCBM and xylan substrate binding are shown in lanes 5-8. The protein bands in lane 6 showed a decrease in protein concentration compared to lane 5 , indicating little or no binding of the enzyme protein with the substrate. No band was observed in lane 7 , indicating that the nonspecifically bound proteins were washed away when the precipitate was washed with buffer. Finally, the bands present in lane 8 showed weaker intensity than those in lanes 5 and 6 , indicating that the amount of enzyme protein that bonded with the substrate was low.

Table 1 The difference in properties between xynADCBM and xynA

\begin{tabular}{llll}
\hline Property comparison & Units & xynADCBM & xynA \\
\hline Optimum pH & 1 & 7.2 & 8.2 \\
$\begin{array}{l}\text { Effect of } \mathrm{Fe}^{3+} \text { on relative } \\
\text { enzyme activity }\end{array}$ & $\%$ & 93.8 & 68.6 \\
$\begin{array}{l}\text { Effect of } \mathrm{Zn}^{2+} \text { on relative } \\
\text { enzyme activity }\end{array}$ & $\%$ & 76.5 & 105.3 \\
$\begin{array}{l}\text { Effect of Co }{ }^{2+} \text { on relative } \\
\text { enzyme activity }\end{array}$ & $\%$ & 191.2 & 37.2 \\
$\begin{array}{l}\text { *Relative enzyme activity of } \\
\text { wheat bran xylan as substrate }\end{array}$ & $\%$ & 90 & 110.9 \\
$\begin{array}{l}\text { Relative enzyme activity of } \\
\text { bean stalk xylan as substrate }\end{array}$ & $\%$ & 89 & 106.9
\end{tabular}

*The ratio of xylanase activity for other substrates and the activity for birchwood xylan was defined as relative enzyme activity. The results presented are the average of 3 individual experiments 


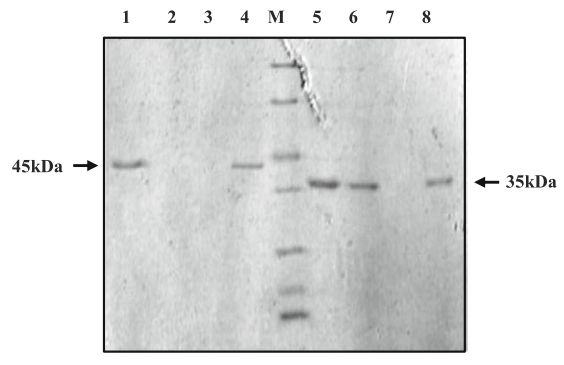

(a)

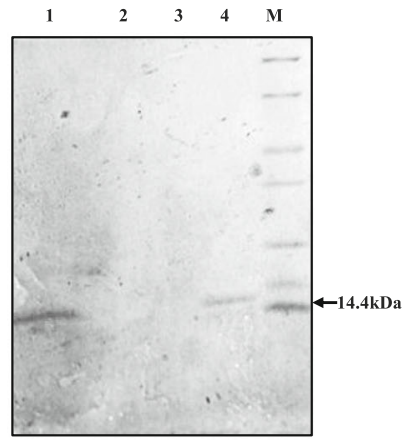

(b)

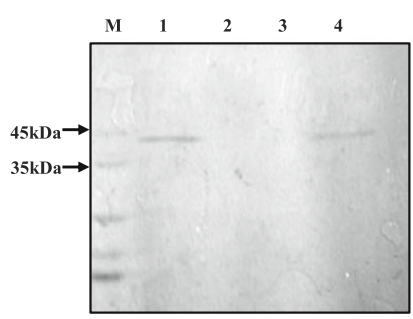

(c)

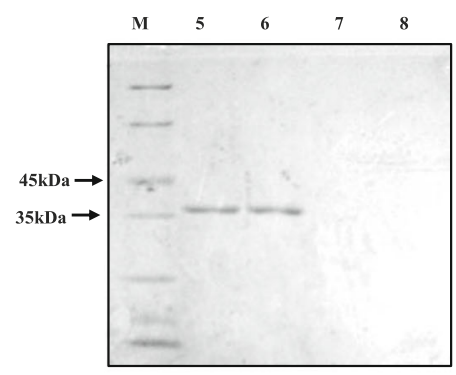

(d)

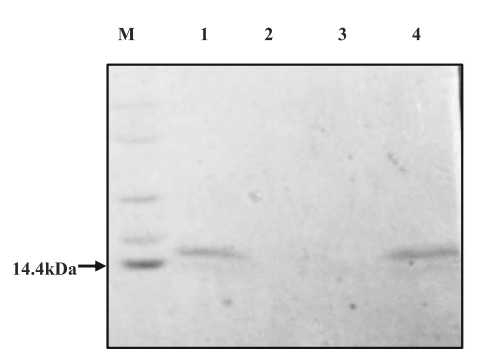

(e)
Fig. 4 Recombinant protein enzyme of $x y n A$, xynADCBM, and CBM binding to xylan and avicel substrate. a xynA and xynADCBM binding to xylan. 1-4, xynA binding to xylan. M, marker; 1, control protein; 2, supernatant (unbound protein); 3, precipitated eluent (nonspecific binding protein); 4, precipitated eluent after denaturation (substrate binding protein); $5-8$, xynADCBM binding to xylan. 5, control protein; 6, supernatant (unbound protein); 7 , precipitated eluent (nonspecific binding protein); 8, precipitated eluent after denaturation (substrate binding protein). b CBM binding to xylan. M, marker; 1, control protein; 2, supernatant (unbound protein); 3, precipitated eluent (nonspecific binding protein); 4, precipitated eluent after denaturation (substrate binding protein). c xynA binding to avicel. $M$, marker; 1, control protein; 2, supernatant (unbound protein); 3, precipitated eluent (nonspecific binding protein); 4, precipitated eluent after denaturation (substrate binding protein). $\mathbf{d}$ xynADCBM binding to avicel. $M$, marker; 1 , control protein; 2, supernatant (unbound protein); 3, precipitated eluent (nonspecific binding protein); 4, precipitated eluent after denaturation (substrate binding protein). e CBM binding to avicel. $M$, marker; 1, control protein; 2, supernatant (unbound protein); 3, precipitated eluent (nonspecific binding protein); 4, precipitated eluent after denaturation (substrate binding protein)

As shown in Fig. 4b, the binding of CBM and the xylan substrate produced no protein band in lane 2, indicating that the CBM bound almost completely to the substrate. Moreover, no protein bands were present in lane 3 , indicating that all nonspecifically bound proteins had been removed by the washing buffer. Lane 4 showed the removal of specific binding of the enzyme protein after SDS-boiling denaturation from the substrate.

Overall, the results shown in Fig. 4a, b and S3 indicate that CBM may influence the binding of xylanase to the $x y-$ lan substrate, which may facilitate the binding of the substrate. After removal of the CBM structure, the affinity of xylanase to xylan substrates showed a significant decrease (lane 6 in Fig. 4a). As shown in Fig. 4b, the recombinant single CBM structure has a strong binding affinity for the substrate, further supporting these results.

In addition, the binding of xynA, xynADCBM, and single CBM to microcrystalline cellulose was also studied. The results showed that the CBM domain also had significant effects on the binding of the enzyme to the cellulose substrate. When the enzyme contains the CBM domain, it can bind the cellulose substrate, while when the CBM domain is removed, almost no binding to the cellulose substrate occurs (Fig. 4c-e).

\section{Analysis of the enzymatic hydrolysis products of xynA and its derivatives}

Table 2 shows the hydrolysis (milligrams per milliliter) of xylose, xylobiose, xylotriose, and xylotetraose in different hydrolytic enzymes. Table 2 and Figure S4 (a) document the xynA and xynADCBM hydrolysis of oat xylan hydrolyzate under the same enzymatic conditions. The results revealed that the original substrate (SigmaAldrich Co., USA) without enzyme (blank) contained 
Table 2 The content of xylooligosaccharide in the hydrolysate using oat spelt xylan and beechwood xylan as the substrate

\begin{tabular}{|c|c|c|c|c|c|c|c|c|}
\hline \multirow{2}{*}{$\begin{array}{l}\text { Substrate } \\
\text { Produces }\end{array}$} & \multicolumn{4}{|c|}{ Oat spelt xylan } & \multicolumn{4}{|c|}{ Beechwood xylan } \\
\hline & $\begin{array}{l}\text { Xylose (mg/ } \\
\mathrm{mL} \text { ) }\end{array}$ & $\begin{array}{l}\text { Xylobiose (mg/ } \\
\mathrm{mL})\end{array}$ & $\begin{array}{l}\text { Xylotriose (mg/ } \\
\mathrm{mL} \text { ) }\end{array}$ & $\begin{array}{l}\text { Xylotetraose } \\
(\mathrm{mg} / \mathrm{mL})\end{array}$ & $\begin{array}{l}\text { Xylose (mg/ } \\
\mathrm{mL} \text { ) }\end{array}$ & $\begin{array}{l}\text { Xylobiose (mg/ } \\
\mathrm{mL} \text { ) }\end{array}$ & $\begin{array}{l}\text { Xylotriose (mg/ } \\
\mathrm{mL} \text { ) }\end{array}$ & $\begin{array}{l}\text { Xylotetraose } \\
(\mathrm{mg} / \mathrm{mL})\end{array}$ \\
\hline Blank $^{*}$ & ND & $0.452^{\mathrm{b}}$ & $0.289^{\mathrm{a}}$ & $0.121^{\mathrm{a}}$ & ND & $0.628^{c}$ & $0.032^{\mathrm{b}}$ & $0.427^{\mathrm{a}}$ \\
\hline xynADCBM & $0.041^{a}$ & $0.827^{\mathrm{a}}$ & $0.125^{b}$ & $0.076^{b}$ & ND & $0.863^{\mathrm{a}}$ & $0.094^{\mathrm{a}}$ & ND \\
\hline xynA & ND & $0.401^{b}$ & $0.299^{a}$ & $0.116^{\mathrm{a}}$ & ND & $0.702^{b}$ & ND & $0.105^{b}$ \\
\hline
\end{tabular}

"Origin substrate (Sigma-Aldrich Co.,USA) without enzyme. Means with the same superscript letter are not significantly different $(p<0.05)$

xylobiose, xylotriose, and a small amount of xylotetraose but no xylose. The xynADCBM hydrolyzed oat xylan substrates to xylooligosaccharides and mostly xylobiose and xylotriose. The hydrolysis ability of oat xylan was greater than that of xynA, with over $62.8 \%$ of xylotetraose, and most of the xylotriose in oat xylan were hydrolyzed to xylobiose, which increased 1.83 times compared to the blank sample.

Table 2 and Figure S4 (b) describe the xynA and xynADCBM hydrolysates of the beechwood xylan substrate under the same enzymatic conditions. The results were similar to those of oat xylan, with xynADCBM having a strong ability to hydrolyze xylotetraose and xylotriose, which resulted in a greater than $37.4 \%$ increase in the xylobiose content in the hydrolysate compared to the blank, while xynA only increased by $11.8 \%$.

\section{Discussion}

\section{The enzyme affinity of the substrate}

The CBM enables the enzyme to bind to the substrate. In many cases, it is linked to a catalytic center through a large number of hydroxyl amino acids, which are not involved in catalysis. The CBM of xylanase is similar to that of cellulase in function and amino acid composition. For some xylanase combined with cellulose, the function of CBM is not necessary for catalysis, but it can regulate the specific activity of enzymes to insoluble and soluble cellulose substrates. Even though in the xylanase D produced by Cellulomonas fimi ( $C$. fimi), the CBM can effectively reduce the $K m$ value; the full-length xylanase $\mathrm{D}$ and the xylanase D without CBM have the equivalent hydrolysis activity to xylan in the wastes of the paperpulp industry (Pakarinen et al. 2014). It has been proposed that the CBM of some xylanases can increase their activity on the insoluble substrate. One view is that CBM increases the effective enzyme concentration on the surface of the substrate. An alternative perspective is that CBM plays a role in fracturing the combination structure of non-covalent bonds between xylanase and increases the probability of substrate contact with the enzyme (Maigisondi et al. 2015). It has been speculated that the non-catalytic structure of CBM may be related to the affinity of xylanase with polysaccharide substrate observed in previous studies (Ponyi et al. 2000; Crouch et al. 2016).

In this study, it is shown that xynADCBM, which lacks the CBM structure, can influence the enzyme affinity of the substrate. The properties of xynADCBM and xynA of different molecular weights prove that the properties of the two enzymes are similar. The negative effect of heavy metals, such as $\mathrm{Fe}^{3+}, \mathrm{Co}^{2+}, \mathrm{Mn}^{2+}, \mathrm{Ag}^{2+}$, and $\mathrm{Cu}^{2+}$, on xylanases activities has been reported (Juturu and Wu 2012). Inhibition by heavy metal ions such as $\mathrm{Co}^{2+}$ may occur due to the formation of a complex with the reactive groups of the enzyme. Metals from group Ilb exhibit high affinity for $\mathrm{SH}, \mathrm{CONH}_{2}, \mathrm{NH}_{2}, \mathrm{COOH}$, and $\mathrm{PO}_{4}$ (Heinen et al. 2014). So it also inhibits the activity of xynA $(44 \mathrm{kDa})$. However, the effects of $\mathrm{Co}^{2+}$ ions on the enzyme activity of xynADCBM are significantly different from that on xynA. $\mathrm{Co}^{2+}$ has an effect on promoting the activity of xynADCBM $(34 \mathrm{kDa})$. The reason of the influence of $\mathrm{CO}^{2+}$ on enzyme activity of xynADCBM needs further study. The reason could be that $\mathrm{CO}^{2+}$ is similar to $\mathrm{Mn}^{2+}$ in improving enzyme activity. It is involved in the stability of the molecular structure of the xynADCBM, which removes the CBM structure, and prevents its conformation from changing during the catalytic reaction, thus improving the reaction rate and increasing its activity (Alam et al. 2005). Another reason could be that the mechanism of $\mathrm{CO}^{2+}$ is similar to that of $\mathrm{Mg}^{2+}$ and $\mathrm{Cu}^{2+}$. It combines with other amino acid attachment points in the enzyme protein structure of xynADCBM except the active site to form a chemical bond with stable structure, so as to improve the corresponding enzyme activity (Iftikhar et al. 2012).

In addition, xynA can significantly improve the hydrolysis efficiency of wheat bran, bean stalk, and wood xylan substrate, probably because the CBM structure can change the enzyme affinity to the substrate. However, it is necessary to reduce the affinity of xylanase binding to cellulose substrate as much as possible in some industrial fields, such as the paper industry, which widely uses xylanase in the pulp bleaching pretreatment (Zhao et al. 2010; Bunterngsook et al. 2015). Our data suggest that xynADCBM, as the truncated derivative comparable to xynA, can be used for pulp bleaching pretreatment in the paper industry. Alternatively, other variants of the enzyme with a modified CBM structure 
could be modified to reduce the affinity of xylanase binding to cellulose substrate as much as possible.

\section{Removing the CBM is more likely to produce xylobiose in a hydrolysis substrate}

Some results indicated that xynADCBM with no CBM structure had better hydrolytic activity for two substrates and stronger substrate hydrolytic specificity for xylotetraose and xylotriose than the intact enzyme. The release of functional xylooligosaccharides (xylobiose (X2) and xylotriose (X3) as the main effective components) from xylan in the hydrolysis mixture may be useful for the preparation of industrial oligosaccharides (Antoine et al. 2004). This would be an effective way to add value to the hemicellulose material of agricultural waste recycling (Samanta et al. 2015). The content of xylobiose increased significantly in the presence of xynADCBM compared with xynA. Since the total length of xynA is divided into three segments, i.e., the signal peptide, catalytic structure, and CBM, all of the CBMs characterized to date have structures based on different $\beta$-sheet topologies (Mattinen et al. 2010). Removing the CBM, making xynADCBM, increases the ability of the enzyme to act on the -C-C-position of the carbon atoms, which increases the chances of producing xylobiose from the hydrolysis of the substrate. Hashimoto et al. also reported that the CBM hampering the catalytic domain could increase the affinity of enzyme to substrate and that the increase of affinity between enzyme and substrate results in the decrease of enzyme activity (Hashimoto et al. 2000).

\section{Conclusion}

The xynA enzyme, a member of the family GH10 of xylanases, in addition to its xylanolytic activity, displays activities against the xylan substrate previously thought to be specific to the affinity of binding to the cellulose substrate (Zhao et al. 2017). It has been suggested that the derivative xynADCBM without CBM components can lead to the production of quality paper in the paper industry for pulp bleaching pretreatment. The xylanase xynA from Streptomyces chartreusis L1105 can hydrolyze xylan to produce xylooligosaccharides such as wheat bran and soybean stalk xylan substrate to some extent, while the hydrolysis efficiency of xynADCBM (without CBM) was higher than that of xynA.

\section{Supplementary information}

Supplementary information accompanies this paper at https://doi.org/10. 1186/s13213-020-01560-1.

Additional file 1: Figure S1. The conserved sequence of xynA. Figure

S2. The sequence of $x y n A-C o r e$. Figure S3. The schematic approach to distinguish specific and nonspecific binding between enzyme and substrate. Figure S4. The chromatogram of Xylooligosaccharide in the hydrolysate using (a) oat spelt xylan and (b) beechwood xylan as the substrate. Table S1. Degenerate primers for the core sequence of xynA. Table S2. HiTAIL-PCR reaction system. Table S3. Thermal Conditions for HiTAIL-PCR. Table S4. Summary of xylanase purification of xynA and xynADCBM

\section{Acknowledgements}

Not applicable.

\section{Authors' contributions}

$\mathrm{KX}$ and BgS conceived and designed the experiments. ZXY, JyL, and LG performed the experiments. PgP analyzed the data. LD and JyL contributed reagents/materials/analysis tools. KX wrote the paper. The authors read and approved the final manuscript.

\section{Funding}

This study was funded by the National Key R\&D Program of China (supported No. 2017YFC1600605), National Natural Science Foundation (supported No. 31601408), Beijing Natural Science Foundation (supported No. 6172003), and Scientific \& technological innovation service capability construction project (supported No. PXM2018_014213_000033).

Availability of data and materials

All data generated or analyzed during this study are included in this published article.

Ethics approval and consent to participate

Not applicable. This work does not contain any studies with human participants or animals performed by any of the authors.

\section{Consent for publication}

Not applicable. Informed consent was obtained from all individual participants included in the study.

\section{Competing interests}

The authors declare that they have no competing interests.

\section{Author details}

${ }^{1}$ Beijing Innovation Centre of Food Nutrition and Human, Beijing Technology \& Business University (BTBU), No. 33 Fucheng Road, Haidian, Beijing 100048, China. ${ }^{2}$ Beijing Laboratory for Food Quality and Safety, Beijing Technology \& Business University (BTBU), No. 33 Fucheng Road, Haidian, Beijing 100048,

China. ${ }^{3}$ Beijing Engineering and Technology Research Center of Food Additives, Beijing Technology \& Business University (BTBU), No. 33 Fucheng Road, Haidian, Beijing 100048, China. ${ }^{4}$ Beijing Key Laboratory of Flavor Chemistry, Beijing Technology and Business University (BTBU), Beijing 100048, China

Received: 28 October 2019 Accepted: 6 March 2020

Published online: 30 March 2020

\section{References}

Alam SI, Dube S, Reddy GSN et al (2005) Purification and characterization of extracellular protease produced by Clostridium sp. from Schirmacher oasis, Antarctica [J]. Enzyme Microb Tech 36:824-831

Antoine C, Peyron S, Lullien V, Abécassis J, Rouau X (2004) Wheat bran tissue fractionation using biochemical markers. J Cereal Sci 39:387-393

Bergquist PL, Reeves RA, Gibbs M (2005) Degenerate oligonucleotide gene shuffling (DOGS) and random drift mutagenesis (RNDM): Two complementary techniques for enzyme evolution. Biomol Eng 22:63-72

Bian J, Peng F, Peng XP, Pai P, Xu F, Sun RC (2013) Structural features and antioxidant activity of xylooligosaccharides enzymatically produced from sugarcane bagasse. Bioresour Technol 127:236-241

Black G, Rixon JE, Clarke J, Hazlewood GP, Theodorou M, Morris P et al (1996) Evidence that linker sequences and cellulose-binding domains enhance the activity of hemicellulases against complex substrates. Biochem J 319:515-520

Bunterngsook B, Eurwilaichitr L, Thamchaipenet A, Champreda V (2015) Binding characteristics and synergistic effects of bacterial expansins on cellulosic and hemicellulosic substrates. Bioresource Tech 176:129-135 
Chitte R, Dey S (2001) Potent fibrinolytic enzyme from a thermophilic Streptomyces megasporus strain SD5. Lett Appl Microbiol 31:405-410

Chivero ET, Mutukumira AN, Zvauya R (2001) Partial purification and characterisation of a xylanase enzyme produced by a micro-organism isolated from selected indigenous fruits of Zimbabwe. Food Chem 72:179-185

Crouch LI, Aurore L, Walton PH, Davies GJ, Gilbert HJ (2016) The contribution of non-catalytic carbohydrate binding modules to the activity of lytic polysaccharide monooxygenases. J Biol Chem 291:7439-7449

Deesukon W, Nishimura Y, Harada N, Sakamoto T, Sukhumsirichart W (2011) Purification, characterization and gene cloning of two forms of a thermostable endo-xylanase from Streptomyces sp SWU10. Process Biochem 46:2255-2262

Falck P, Precha-Atsawanan S, Grey C, Immerzeel P, Stálbrand H, Adlercreutz P et al (2013) Correction to Xylooligosaccharides from Hardwood and Cereal Xylans Produced by a Thermostable Xylanase as Carbon Sources for Lactobacillus brevis and Bifidobacterium adolescentis. J Agric Food Chem 61: 7333-7340

Fu XY, Zhao W, Xiong AS, Tian YS, Peng R (2010) High expression of recombinant Streptomyces sp S38 xylanase in Pichia pastoris by codon optimization and analysis of its biochemical properties. Mol Biol Rep 38:4991-4997

Gibbs MD, Nevalainen KM, Bergquist PL (2001) Degenerate oligonucleotide gene shuffling (DOGS): a method for enhancing the frequency of recombination with family shuffling. Gene 271:13-20

Hashimoto M, Ikegami T, Seino S, Ohuchi N, Fukada H, Sugiyama J, Shirakawa M, Watanabe T (2000) Expression and characterization of the chitin-binding domain of chitinase A1 from Bacillus circulans WL-12. J Bacteriol 182:3045-3054

Heinen PR, Henn C, Peralta RM, Bracht A, De Cássia R, Simão G et al (2014) xylanase from Fusarium heterosporum: Properties and influence of thiol compounds on xylanase activity. Afr J Biotechnol 13:1047-1055

Iftikhar TM, Niaz MA, Zia M et al (2012) Production potential of locally 496 isolated strain of Fusarium solani (MBL 24) for extracellular lipases. Pak J Bot 44:393-397

Juturu V, Wu JC (2012) Microbial xylanases: Engineering, production and industrial applications. Biotechnol Adv 30:1219-1227

Kumar V, Satyanarayana T (2014) Secretion of recombinant thermo-alkali-stable endoxylanase of polyextremophilic Bacillus halodurans, TSEV1 and its utility in generating xylooligosaccharides from renewable agro-residues. Process Biochem 49:1875-1883

Lisov AV, Belova OV, Kovalevskaya Z, Budarina ZI, Solonin A, Vinokurova NG et al (2013) Recombinant xylanase from Streptomyces coelicolor Ac-738: Characterization and the effect on xylan-containing products. World J Microbiol Biotechnol 30:801

Liu LW (2005) Sequence Analysis Molecular Evolution and Molecular Modeling of Xylanase Doctoral thesis, Jiangnan University, pp 35-41

Liu YG, Chen Y (2007) High-efficiency thermal asymmetric interlaced PCR for amplification of unknown flanking sequences. J Biotechniques 43:649

Maigisondi G, Turunen O, Pastinen O, Pahimanolis N, Master ER (2015) Enhancement of acetyl xylan esterase activity on cellulose acetate through fusion to a family 3 cellulose binding module. Enzyme Microb Tech 79-80:27-33

Mattinen M, Kontteli M, Kerovuo J, Drakenberg T, Annila A, Linder M et al (2010) Three dimensional structures of three engineered cellulose binding domains of cellobiohydrolase from Trichoderma reesei. Protein Sci 6:294-303

Michael RG, Joseph S (2012) The Hanahan Method for Preparation and Transformation of Competent E coli: High-Efficiency Transformation. In: John I, Ann B, Alexander G (eds) Molecular cloning a laboratory manual, 4th edn. Cold Spring Harbor Laboratory Press, New York, pp 162-168

Miller GL (1959) Use of Dinitrosalicylic acid reagent for determination of reducing sugar. Anal Chem 31:426-428

Otieno D, Ahring B (2012) The potential for oligosaccharide production from the hemicellulose fraction of biomasses through pretreatment processes: Xylooligosaccharides (XOS), arabinooligosaccharides (AOS), and mannooligosaccharides (MOS). Carbohydr Res 360:84-92

Padilla-Hurtado B, Flórez-Ramos C, Aguilera-Gálvez C, Medina-Olaya J, RamírezSanjuan A, Rubio-Gómez J et al (2012) Cloning and expression of an endo$1,4-\beta$-xylanase from the coffee berry borer, Hypothenemus hampei. BMC Res Notes 5:1-9

Pakarinen A, Haven MO, Djajadi DT, Várnai A, Puranen T, Viikari L (2014) Cellulases without carbohydrate-binding modules in high consistency ethanol production process. Biotechnol Biofuels 7:27

Petzold-Welcke K, Schwikal K, Daus S, Heinze T (2014) Xylan derivatives and their application potential mini-review of own results. Carbohydr Polym 100:80-88
Ponyi T, Szabo L, Nagy T, Orosz L, Simpson P, Williamson M, Gilbert HJ (2000) Trp22, Trp24, and Tyr8 Play a Pivotal Role in the Binding of the Family 10 Cellulose-Binding Module from Pseudomonas Xylanase A to Insoluble Ligands. Biochem 39:985-991

Ramkrishna DS, Banerjee J, Arora A (2015) Prebiotic potential of oligosaccharides: A focus on xylan derived oligosaccharides. Bioact Carbohydr Diet Fibre 5:19-30

Ravi L, Bhardwaj V, Khanna G (2015) Annoreticuin and sabadelin,a potential oncogenic transcriptional factor inhibitors: An in silico analysis. Pharm Lett 7: 204-212

Ruizarribas A et al (1995) Overproduction, purification, and biochemical characterization of a xylanase (Xys1) from Streptomyces halstedii JM8. J Appl Environ Microbiol 61:2414-2419

Samanta AK, Jayapal N, Jayaram C, Roy S, Kolte AP, Senani S et al (2015) Xylooligosaccharides as prebiotics from agricultural by-products: production and applications. Bioact Carbohydr Diet Fibre 51:62-71

Sermsathanaswadi J, Baramee S, Tachaapaikoon C, Pason P, Ratanakhanokchai K, Kosugi A (2017) The family 22 carbohydrate-binding module of bifunctional xylanase/ß-glucanase xyn10E from paenibacillus curdlanolyticus, B-6 has an important role in lignocellulose degradation. Enzyme Microb Tech 96:75-84

Shin ES, Yang MJ, Jung KH, Kwon EJ, Jung JS, Park SK et al (2002) Influence of the Transposition of the Thermostabilizing Domain of Clostridium thermocellum Xylanase (XynX) on Xylan Binding and Thermostabilization. Appli Environ Microb 68:3496-3501

Sousa S, Pedrosa J, Ramos A, Ferreira PJ, Gamelas JAF (2016) Surface properties of xylan and xylan derivatives measured by inverse gas chromatography. Colloid Surface A 506:600-606

Sun P, Wang X, Alquier L, Maryanoff CA (2008) Determination of relative response factors of impurities in paclitaxel with high performance liquid chromatography equipped with ultraviolet and charged aerosol detectors. J Chromatogr A 1177:87-91

Xiao Z, Grosse S, Bergeron H, Lau PCK (2014) Cloning and characterization of the first GH10 and GH11 xylanases from rhizopus oryzae. Appl Microbiol Biotechnol 98:8211-8222

Zhang Z, Li ZH, Wang F, Fang M, Yin CC, Zhou ZY et al (2002) Overexpression of DsbC and DsbG markedly improves soluble and functional expression of single-chain Fv antibodies in Escherichia coli. Protein Expr Purif 26:218-228

Zhao C, Wu Y, Liu X, Liu B, Cao H, Yu H et al (2017) Functional properties, structural studies and chemo-enzymatic synthesis of oligosaccharides. Trends Food Sci Technol 66:135-145

Zhao W, Zhong Y, Yuan H, Wang J, Zheng H, Wang Y et al (2010) Complete genome sequence of the rifamycin SV-producing Amycolatopsis mediterranei U32 revealed its genetic characteristics in phylogeny and metabolism. Cell Res 20:1096

Zhu Y, Li X, Sun B, Song H, Li E, Song H (2012) Properties of an Alkaline-Tolerant, Thermostable Xylanase from Streptomyces chartreusis L1105, Suitable for Xylooligosaccharide Production. J Food Sci 77:506-511

\section{Publisher's Note}

Springer Nature remains neutral with regard to jurisdictional claims in published maps and institutional affiliations.

Ready to submit your research? Choose BMC and benefit from:

- fast, convenient online submission

- thorough peer review by experienced researchers in your field

- rapid publication on acceptance

- support for research data, including large and complex data types

- gold Open Access which fosters wider collaboration and increased citations

- maximum visibility for your research: over $100 \mathrm{M}$ website views per year

At BMC, research is always in progress.

Learn more biomedcentral.com/submission 